\title{
El ensalmo terapéutico y su tipología
}

El uso de la palabra para conseguir la curación del enfermo es un recurso ancestral. Esta práctica la encontramos ya bien documentada para los griegos del mundo clásico. La epōdē, es decir, la encantación cantada o simplemente recitada, se utilizaba tanto para tratar las heridas del guerrero como para las enfermedades en general ${ }^{1}$. Dentro de la actual medicina popular europea, el ensalmo terapéutico -oración o conjuro ${ }^{2}-$ es todavía muy usual, pudiendo ser empleado tanto por el curandero como por aquellas personas que, sin tener un saber especializado, siguen usando en casa los remedios terapéuticos de tipo credencial que les ha legado la tradición. En nuestros días siguen recitándose - si bien transformados por el tiempo- conjuros de procedencia precristiana, así como un buen número de oraciones terapéuticas surgidas especialmente a lo largo de toda la época en que la medicina y la religión se hallaban intimamente ligadas.

Estos ensalmos se utilizan en determinados procesos terapéuticos junto con rituales de tipo mágico o religioso, o incluso con prácticas propias de la medicina popular de naturaleza empírica. Dentro de la dinámica del proceso curativo, el ensalmo puede desempeñar tanto un papel central - siendo entonces considerado como el elemento más importante e imprescindible del ritual terapéutico- como tener un papel secundario $\mathrm{y}$, en este último caso, su finalidad será simplemente la de reforzar la efectividad de una práctica curativa concreta, ya sea de tipo credencial o de tipo empírico.

\footnotetext{
1 Véase, por ejemplo, Luis GIL, Therapeia. La medicina popular en el mundo clásico (Madrid, 1969), pp. 217-246.

2 Dentro del ámbito de la medicina popular, las denominaciones «ensalmo», «conjuro» y «oración curativa» se utilizan a menudo de manera ambigua utilizándolas en ocasiones como sinónimas. A lo largo de estas páginas entenderé *oración curativa” y «conjuro» como dos variedades diferentes de ensalmos implicando la primera un intento de establecer contacto con el «numen» de forma laudativa o impetrativa, mientras que el conjuro presupone siempre un acto de conminación.
} 
Los ensalmos propios de la medicina popular no forman parte tan sólo del acto curativo en sí, sino que también pueden desempeñar una función profiláctica o bien acompañar los rituales que se efectúan para establecer el diagnóstico. En calidad de profilaxis se puede recitar una determinada oración, llevarla consigo escrita en un papel, que incluso puede coserse en la ropa, o bien fijar en las paredes domésticas hojas impresas -estampadas para esta finalidad- en las que junto a la oración figura una ilustración del santo protector. Por otra parte, en algunos casos concretos, para realizar un diagnóstico determinado será condición necesaria recitar el ensalmo de rigor. Los numerosos y variados rituales de la medicina popular europea destinados a combatir el aojamiento nos proporcionan buenos ejemplos: el ensalmo es, muy a menudo, forzosamente necesario para llegar a saber si una determinada enfermedad es consecuencia directa del mal de ojo ${ }^{3}$.

A todo ensalmo se le otorga un cierto poder inmanente que es al fin y al cabo lo que justifica su uso. De hecho, estas oraciones y conjuros terapéuticos son una manera de canalizar las inagotables fuerzas provenientes del mundo numénico o del ámbito mágico, pero el poder propio que tienen estos ensalmos es innegable, ya que no son sino una de las llaves que dan acceso a estas fuerzas sobrenaturales. Como es bien sabido, a diferencia de las plegarias populares destinadas al culto, las oraciones y conjuros de carácter terapéutico son guardados con mucho celo por sus poseedores. Solamente serán revelados a otras personas en circunstancias muy especiales y siguiendo siempre una estricta normativa fijada por la tradición. Infringir las reglas básicas de transmisión puede acarrear que la oración en cuestión o la persona que se sirve de ella pierdan sus poderes terapéuticos. Muy a menudo, estos ensalmos tan sólo son enseñados ante la muerte inminente de su poseedor ${ }^{4}$, el cual los legará en calidad de «herencia» a una persona de su confianza. En otros contextos culturales se dispondrá de un día al año - generalmente Viernes Santo o Navidad- para poder revelar estos ensalmos sin que

En las prácticas terapéuticas relacionadas con el mal de ojo, el ritual que se efectúa para establecer el diagnóstico desempeña un papel muy importante, llegando con mucha frecuencia a confundirse con el ritual estrictamente curativo. Véase, por ejemplo: Louis C. JONES, "The Evil Eye among European-Americans", Alan DUNDES (ed.), The Evil Eye. A fulklore casebook (New York - London, 1981), p. 161; Josep MarTf́ I PÉrez, L'Alguer. Kulturanthropologische Monographie einer sardischen Stadt (Berlín, 1986), p. 309.

+ Véase, por ejemplo: François LAPLANTINE, La médecine populaire des campagnes aujourd'bui (Paris, 1978); M.' Ángeles DfAz y José Luis SEvilla, «Patología popular y mal de ojom, M. KenNY y J. M. de Miguel (eds.), La antropología médica en España (Barcelona, 1980), p. 216. 
el dador tenga por ello que perder sus facultades curativas 5 . En todo caso, dador y receptor siempre tendrán que estar unidos por lazos familiares o de amistad íntima. En ocasiones existen también normas rígidas que determinan de manera más exacta a quién hay que dar los ensalmos. Así, por ejemplo, en una pequeña población griega estudiada por Dionisopoulos-Mass, los ensalmos que se recitan contra el mal de ojo han de ser pasados a una persona de diferente sexo ${ }^{6}$. Hay que tener, naturalmente, en cuenta que, aparte de las consideraciones de tipo emic que impiden la libre divulgación de los ensalmos, será siempre de interés para el propio poseedor de los conocimientos, salvaguardar el esoterismo que encierra este tipo de prácticas terapéuticas. El hecho de tener acceso a unos poderes curativos determinados conferirá al ensalmador un cierto prestigio respecto a los demás miembros de la comunidad, los cuales en caso de necesidad se verán constreñidos a solicitar su favor. Lógicamente, esta situación privilegiada del ensalmador perdería más relevancia cuanto mayor fuera la difusión de los conocimientos.

Mediante la lenta pero siempre segura difusión de estos ensalmos ya sea oralmente, a través de hojas impresas o debido a la amplia difusión de sus fuentes, en los casos en que procedan por ejemplo de obras religiosas, se forman variantes de un mismo texto original que naturalmente hay que tener en cuenta. Las dos oraciones que podremos ver a continuación, genéticamente emparentadas, se recitan -entre otras finalidades- para asegurar un buen desarrollo del parto. La primera fue recogida en las Islas Canarias, la segunda en Cuba:

San Bartolomé se levantó,
pies y manos se lavó,
por el camino, caminó,
con el Señor se encontró
y estas palabras le habló:
- ¿Dónde vas, Bartolomé?
- En busca de Ti, Señor,
- Vuélvete, Bartolomé,
que yo te daré tal don
que en la casa que tú entres
no caiga piedra ni rayo,

San Bartolomé se levantó, pies y manos se lavó, por el camino, caminó, con el Señor se encontró y estas palabras le habló: - ¿Dónde vas, Bartolomé?

- En busca de Ti, Señor, -Vuélvete, Bartolomé, que yo te daré tal don no caiga piedra ni rayo,

\author{
San Bartolomé se alevantó \\ cuando el primer gallo cantó, \\ sus pies y manos lavó \\ en un monte peregrino \\ su bordón de oro cogió, \\ por un camino caminó \\ en donde Dios se apareció. \\ Le dijo alzando la mano \\ -Ve p'atrás Bartolomé \\ que yo te daré un gran don: \\ donde tú seas mentado
}

5 Véase, por ejemplo: Jane VollES, «Genoese Folkways in a California Mining Camp», California Folklore Quarterly, n." 3 (1944), p. 213; Pierrette BERTRAND-Rousseau, ille de Corse et magie blanche (Paris, 1978), p. 29; J. MARTf I PéreZ, op. cit., p. 303.

6 Cfr. Regina Dionisopoulos-Mass, «The Evil Eye and Bewitchment in a Peasant Village», C. Maloney (ed.), The Evil Eye (New York, 1976), p. 50. 
ni muera mujer en parto,

no caiga piedra ni rayo

ni criatura de espanto ${ }^{7}$.

ni muera mujer de parto

ni niños de espanto

ni hombre de sobresalto.

Amen ${ }^{8}$.

Tal como acontece con la producción de la literatura oral popular en general, la difusión de los ensalmos terapéuticos no se arredra ni ante las fronteras políticas ni ante las lingüísticas. Un buen ejemplo para ello es el siguiente ensalmo contra el aojamiento muy expandido por España:

\title{
País Valenciano
}

\author{
Dos te han hecho mal, \\ y tres te lo tienen que quitar, \\ que son las tres personas \\ de la Santísima Trinidad, \\ Padre, Hijo y Espíritu Santo?.
}

Asturias
Dos te envidiaron, tres te desenvidian;
San Pedro,
San Juan
y San Andrés 10 .

Andalucía

Dos ojos te han hecho mal, y tres te han de sanar, y son los de la Santísima Trinidad, Padre, Hijo y Espíritu Santo. Amén "I.

y también en otros países europeos:

7 Cfr. José A. SÁnChez Pérez, Supersticiones españolas (Madrid, 1948), p. 232.

8 Cfr. José Seonne, Remedios y supersticiones en la provincia de las Villas (La Habana, 1962), pp. 246-247. Véanse también otras variantes del mismo ensalmo en pp. 247248.

9 Cfr. Francisco G. SEIJO, Curanderos y medicina popular (Alicante, 1974), p. 180.

10 Cfr. Constantino Cabal, La mitologia asturiana (Oviedo, 1972), p. 584.

11 Cfr. C. CABAL, op. cit., p. 585. 
Alemania (Baja Sajonia)

Haben Dich zwei schlechte Augen gesehen, so sehe Dich jetzt drei Paar gute Augen wie der Christus, Petrus und Johannes.

Es segne Dich die alleheiligste Dreifaltigkeit, Gott Vater, Sohn und Heiliger Geist 12.

Italia (Saboya)

Dos ojos te han embrujado tres quieren ayudarte santa Ana, santa Elena, santa Magdalena 13.

Grecia (archipiélago de las Espóradas)

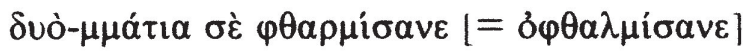

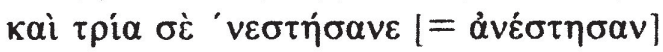

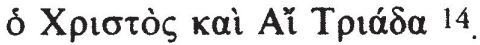

A través de la difusión de un determinado ensalmo, no tan sólo se producen las lógicas variaciones formales, sino que incluso su finalidad misma puede verse alterada. La primera de las oraciones que ofrecemos a continuación procede de Asturias y se utiliza para sanar el «mal de rana» ${ }^{15}$; la segunda fue recogida en Córcega y su finalidad es la de cortar las hemorragias. La base genética común de estas dos oraciones es evidente:

12 «Te han visto dos malos ojos, / así te vean ahora tres pares de ojos buenos / como los de Cristo, Pedro y Juan, / Que te bendiga la Santísima Trinidad, / Dios Padre, Hijo y Espíritu Santo.» Esta oración, hasta el momento todavía inédita, fue recogida de boca de un curandero en agosto de 1987 en un pequeño pueblo de la región de Cloppenburg (Baja Sajonia).

13 Desgraciadamente no pude tener acceso a la versión original en lengua italiana de este ensalmo. Cfr. Ernesto de Martino, Katholizismus, Magie, Aufklärung (München, 1982), p. 23.

14 «Dos ojos te han embrujado / y tres te han restablecido, / Cristo y la Santísima Trinidad». Cfr. Siegfried SeligmanN, Der böse Blick und Verwandtes (Berlin, 1910), I, p. 378.

15 Según C. Cabal, el «mal de rana» resulta de la picadura de un «bicho» a la lengua de la vaca: $o p$. cit., p. 570. 


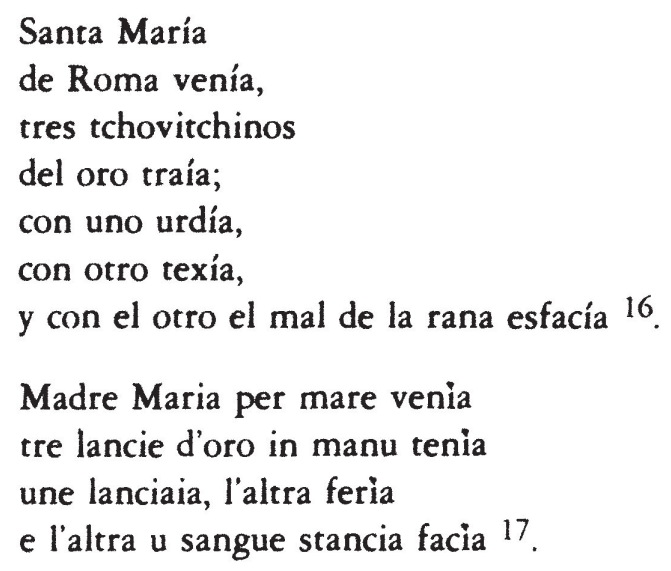

También de interés son las dos oraciones catalanas siguientes, recitada la primera para los "golpes de aire» malsanos (comarca del Panadés) y la segunda para sanar el abatimiento (Rosellón):

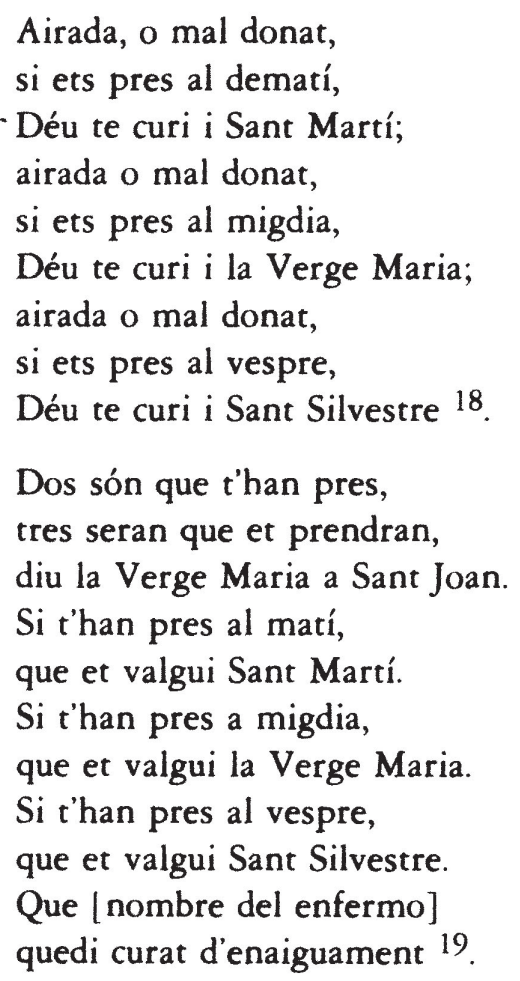

16 Cfr. C. CABAL, op. cit., p. 570.

17 «Madre María por mar venía / tres lancetas de oro en la mano tenía / una lanzaba, la otra hería / y la otra la sangre detenía.» Cfr. P. Bertrand-Roussenu, op. cit., p. 68 . Véase también la variante de la p. 38.

18 «Golpe de aire o brujería, si te han cogido por la mañana, / Dios te cure y San Martín; / golpe de aire o brujería, / si te han cogido al mediodía, / Dios te cure y la Virgen María; / golpe de aire o brujería, / si te han cogido al anochecer, / Dios te cure y San Silvestre.» Cfr. Joan AMADES, Folklore de Catalunya. Costums i creences (Barcelona, '1980), p. 961.

19 «Dos son los que te han cogido, tres serán los que te cogerán, / dice la Virgen 
De hecho, se trata de dos oraciones cuya finalidad original sería, lo más seguro, la de combatir el aojamiento, pero muy posiblemente, ante la progresiva desaparición de la creencia del mal de ojo en aquellas comarcas catalanas, han perdido su primitiva función. Joan Amades nos ofrece otra variante muy parecida - bastante extendida en Cataluñala cual empieza con el verso: «Si estàs ullprés del dematí...» ( Si te han aojado por la mañana...») ${ }^{20}$. En este caso, pues, la conexión de la oración con la creencia del mal de ojo es evidente, si bien hay que mencionar que, según Joan Amades, esta oración no se recita tan sólo contra el mal de ojo, sino también - seguramente dependiendo de la localidad de procedencia - contra hechicería, abatimiento, golpes de aire y dolores de vientre ${ }^{21}$, enfermedades estas últimas que quizá en un principio se podrían considerar causadas por el mal de ojo. Conocemos asimismo una oración en lengua castellana recogida en el País Valenciano que se emplea contra el aojamiento y que se halla indudablemente relacionada con las variantes catalanas que hemos visto:

Si te han tomado de ojo por la mañana,
que te lo quite la abuela Santa Ana.
si te han tomado de ojo a mediodía,
que te lo quite la Virgen María.
Si te han tomado de ojo por la tarde,
que te lo quite la Virgen del Carmen.
Si te han tomado de ojo por la noche,
que te lo quite San Roque 22 .

Dentro de la medicina popular europea encontramos una gran variedad de ensalmos, lo que, por otra parte, no impide que según el carácter del texto podamos clasificarlos en un reducido número de tipos básicos. De esta manera, podemos distribuir los ensalmos con finalidad terapéutica en los siguientes grupos:

\footnotetext{
María a San Juan. / Si te han cogido por la mañana, / que te valga San Martín. / Si te han cogido al mediodía, / que te valga la Virgen María. / Si te han cogido al anochecer, / que te valga San Silvestre. / Que... [nombre del enfermo] quede curado del abatimiento.» Cfr. Henri GuITER, «Conjurations bénéfiques en Roussillon», Actes du 99" Congrès National des Sociétés Savantes (Besançon, 1974) (Paris, 1977), p. 308.

20 Cfr. Joan Amades, op. cit., p. 953.

21 Cfr. ibidem.

22 Cfr. F. G. SEIJO, op. cit., p. 178.
} 


\section{Narrativos}

Se trata de ensalmos de tipo historiado o narrativo cuyo argumento nuclear procede, no raramente, de leyendas hagiográficas populares. Lo importante en el contenido narrativo es que siempre se hace mención de la dolencia que hay que tratar. Este tipo de ensalmos lo encontramos, sin lugar a dudas, muy difundido por toda Europa:

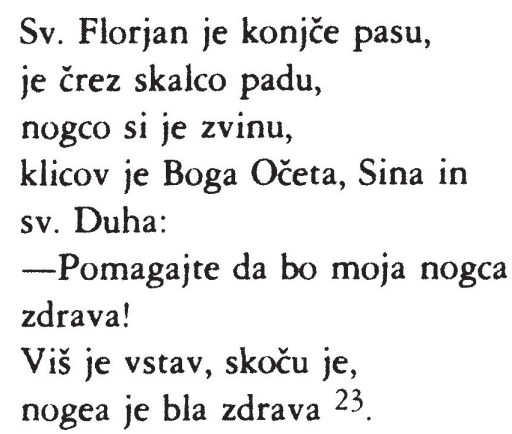

Esta oración propia de los eslovenos de Carintia se usa para la curación de las dislocaciones. Con la misma finalidad se recita también la siguiente oración alemana (Baja Sajonia):

Als Jesus und Maria nach Jerusalem ritten, kamen sie vor einer hohen steilen Brücke; das Füllen vertrat sich den Fuss. Da stieg unser lieber Herr Jesus herunter und segnete ihn von oben bis zu den Füssen, von Gliedern zu Gliedern, von Adern zu Adern, dass es nicht "kelt" und auch nicht schwillt, dass es so langsam vorüber geht. Dann ging Maria und ihr liebes Kind Jesus hinüber. Im Namen Gottes, des Vaters, des Sohnes und des Heiligen Geistes 24.

23 «San Florián custodiaba caballos / en el prado, / se cayó de una roca, / se dislocó el pie, / invocó a Dios Padre, Hijo y Espíritu Santo: / -Ayudadme para que mi pie sane! / Se levantó, dio un salto, / el pie había sido curado.» Cfr. Pavel Košlr y Vinko MÖDERNDORFFR, «Die volksmedizin bei den Kärnter Slowenen», Elfriede Grabner (ed.), Volksmedizin. Probleme und Forschungsgeschichte (Darmstadt, 1967), p. 67.

24 «Cabalgando Jesús y María hacia Jerusalén llegaron ante un puente alto y empinado; el caballo se dislocó una pata. Entonces nuestro querido Jesús descendió y lo bendijo de arriba hasta los pies, de miembro a miembro, de vena a vena, de manera que ni duela ni se hinche, que poco a poco vaya desapareciendo el mal. Entonces, María y su querido niño Jesús pasaron el puente. En nombre de Dios Padre, del Hijo y del Espíritu Santo.» Cfr. Josep MARTf I PÉREz, «Curanderos y oraciones curativas de la región de Cloppenburg. Algunas consideraciones sobre "lo irracional" en la medicina popular», Ethnica, 20 (1984), p. 184. 
En la oración sarda que podremos ver a continuación se hace referencia a una leyenda hagiográfica muy difundida en el sur de Italia según la cual un santo, encontrándose de viaje, pidió a un matrimonio que lo albergara en su casa. Mientras que el marido se mostró deferente en todo momento hacia el huésped, la mujer, en cambio, le dispensó un comportamiento grosero y esquivo, por lo que el santo la castigó haciéndole sentir fuertes dolores de vientre ${ }^{25}$.

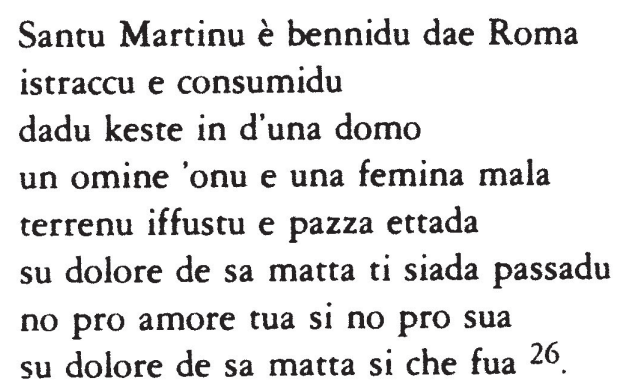

Haciendo eco de la leyenda, esta oración sarda - concretamente de la región del Logudoro- se recita con la finalidad de aliviar los dolores del vientre.

Muy a menudo, estos tipos de ensalmos incorporan un pequeño diálogo en el texto:

Oración contra el dolor (Cataluña)

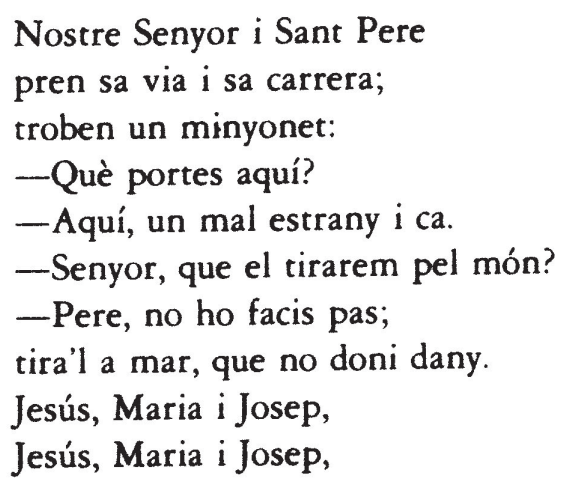

25 El nombre del santo al que se refiere la leyenda cambia según la versión. Véase: De Martino, op. cit., pp. 40-41. También en Cataluña encontramos ensalmos terapéuticos que parecen derivarse de esta leyenda. Véase, por ejemplo: J. AMADES, op. cit., pp. 980 y 981 .

26 «San Martín ha venido de Roma / cansado y consumido / ha ido a parar a una casa / un hombre bueno y una mujer mala / suelo mojado y paja esparcida / el dolor de vientre te pase / no por amor tuyo sino por amor suyo / el dolor de vientre que se vaya." Cfr. Mario ATZORI y M.* Margherita SATTA, Credenze e riti magici in Sardegna (Sassari, 1980), p. 110. 
Jesús, Maria i Josep, alabat sia el cor de Maria, alabat sia el cor de Jesús, alabat sia el cor de Maria Puríssima, que no visquem ni moriguem en pecat mortal. Amén ${ }^{27}$.

\section{Oración para sanar las heridas (Alemania)}

Es fährt Peter auf einem Pferdschen,

Christus auf einem Eselschen.

- Peter, fahre! - Herr, ich kann nicht.

-Warum? - Meinem Pferdschen brach ein Fuss.

-Peter, erzähle eine Geschichte!

- Herr, ich kann nicht!

-Peter, sage mir nach:

Haut zu Haut, Blut zum Blute,

Ader zur Ader, Haar zum Haar,

Knochen zum Knochen, Mark zum Marke.

Und alles, was in dem Gliede enthalten ist!

Dazu verhelfe mir Gott der Vater! 28.

\section{1.a. Mnemotécnicos}

Dentro del mismo grupo de los ensalmos narrativos, encontramos un tipo particular de oraciones en las que, a lo largo de la exposición narrativa, se nos describe someramente el procedimiento de carácter empírico o credencial propio para curar la enfermedad en cuestión:

\section{Oración para tratar la erisipela (Galicia)}

27 «Nuestro Señor y San Pedro / van haciendo camino; / encuentran a un chiquillo: / - Qué traes aquí? / - Aquí, un mal extraño. / -Señor, ¿lo echaremos por el mundo? / - Pedro, no lo hagas; échalo al mar que no haga daño. / Jesús, María y José, |tres veces| /alabado sea el corazón de María, / alabado sea el corazón de Jesús, / alabado sea el corazón de María Purísima, / que no vivamos ni muramos en pecado mortal. Amén.» Cfr. J. Amades, op. cit., p. 965.

28 «Pedro cabalga en un caballito, / Cristo en un burrito. / -Pedro, ¡cabalga! -Señor, no puedo. / - ¿Por qué? - Mi caballito se rompió una pata. / - Pedro, ¡cuéntame una historia! / -Señor, ¡no puedo! / - Pedro, di después de mí: Vena a vena, pelo a pelo, / hueso a hueso, tuétano a tuétano. / ¡Y todo lo que contengan los miembros! / Para ello que me ayude Dios Padre.» Cfr. Heinrich VORwAHL, «Deutsche Volksmedizin in Vergangenheit und Gegenwart», E. GRABNER (ed.), op. cit., p. 243. 
Pedro Pablo foi a Roma

Pedro Pablo véu da-lá.

A Jesucristo encontróu,

Jesucristo lle preguntóu:

- ¿Pedro Pablo, que hai alá?

- Señor, hai moita Decipla e Decipela,

moita xente morre de-la.

-Vai alá e bendícea

con: auga da fonte,

esparto do monte,

sal da salina

e-aceite de oliva.

Por a gracia de Dios

e da Virgen María,

un padrenuestro

e-unha avemaría 29.

\section{Oración contra las picaduras de insectos (Córcega)}

C'eranu Cristu e Sistu

Cristu sente briunà un cristianu e dice:

-O Sisțu, vai e affacadi

chi sentu briunà un cristianu!

Sistu parte allegru e volti tristu.

Cristu dice:

-Chi hai, O Sistu?

Si andatu allegru e volti tristu?

-U ladru di Silvanu

ha puntu u poveru cristianu!

- Volta e dilli che lu faci:

saliva di corpu e terre pisente

insinu a dumane ch'un n'avera niente! 30 .

\section{Oración contra el mal olor de la boca (Alemania)}

29 «Pedro Pablo fue a Roma. / Pedro Pablo vino de allá. / A Jesucristo encontró, / Jesucristo le preguntó: / - ¿Pedro Pablo, qué hay allá? / - Señor, hay mucha erisipela, / mucha gente muere de ella. / - Ve allá y bendícela / con: agua de fuente, / esparto de monte, / sal de salina / y aceite de oliva. / Por la gracia de Dios / y de la Virgen María, / un padrenuestro / y una avemaría.» Cfr. V. LIS QUIBEN, La medicina popular en Galicia (Madrid, '1980), p. 127.

30 «Érase Cristo y Sisto / Cristo oye gemir a un cristiano y dice: / -Oh Sisto, ve a ver / que oigo gemir a un cristiano! / - ¿Qué tienes, oh Sisto? / ¿Te has ido alegre y has vuelto triste? / -Este ladrón de Silvano / ha punzado a un pobre cristiano! / -Vuelve y di que haga: / Saliva de cuerpo y barro / hasta mañana y no tendrá nada.m Cfr. P. Bertrand-Rousseau, op. cit., p. 78. 
Ging der heilige Job auf dem Mist, kommt zu ihm der Herr Jesu Christ. Sagt zu ihm Herr Jesu Christ, warum er so traurig ist. -Ach, warum soll ich nicht traurig sein? -geht doch mein ganzer Mund in Faul. Sagt zu ihm Herr Jesu Christ: - Nimm drei Strohhalm aus dem Mist und zieh sie durch dein Maul ${ }^{31}$.

Este tipo de ensalmos mnemotécnicos hay que incluirlos en los de tipo narrativo porque siempre se presentan como parte integrante de ellos. El procedimiento terapéutico que se describe es precisamente el que se lleva a cabo durante el ritual.

\section{Impetrativos}

La fórmula rogativa puede, naturalmente, darse en diferentes tipos de oraciones terapéuticas, pero los ensalmos que podemos denominar «impetrativos» se caracterizan por contener un texto con la forma exclusiva de plegaria, siendo ésta dirigida a un personaje celestial determinado al que se le implora la curación del enfermo:

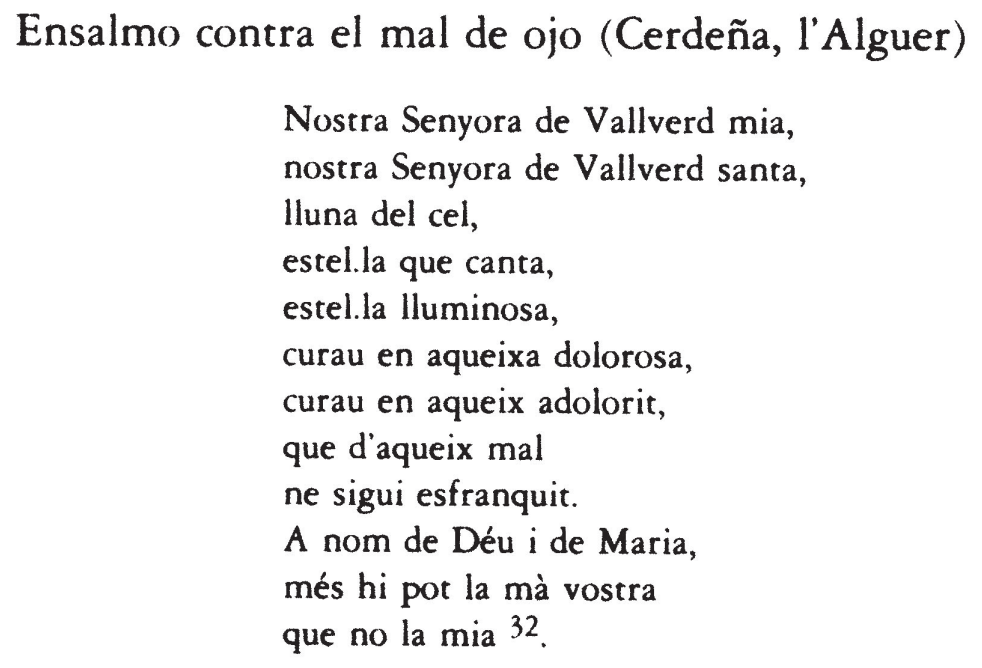

31 «Estaba San Job por el estercolero, / va a él Nuestro Señor Jesucristo. / Le dice Nuestro Señor Jesucristo, / que por qué está tan triste. / - Ay, ¿por qué no tengo que estar triste? / toda mi boca huele mal. / Le dice Nuestro Señor Jesucristo: / -Toma tres pajitas del estercolero / pásatelas por la boca.» Cfr. Heinrich MARZELL, «Die Volksmedizin», Adolf SPAMER (ed.), Die deutsche Volkskunde (Leipzig, 1934), I, p. 179.

32 «Nuestra Señora de Vallverd mía, / nuestra Señora de Vallverd santa, / luna 
Ensalmo para combatir las lombrices intestinales (Galicia):
Virgen Santa que me ve curar a un anxeliño do ceo, pol-las llagas que sofréu noso Señor no Calvario, dame forzas para matar as lombrigas que padece, e que non lle volvan máis a este anxeliño qu-é teu, padecendo Lombrigueiro 33.

\title{
3. Laudativos
}

En los procesos curativos se emplean también oraciones que de manera explícita no contienen ningún ruego (aunque lógicamente el hecho de recitarlas presupone siempre una petición), sino que poseen un contenido exclusivamente laudativo en honor al personaje celestial al que se le pide la curación. Este tipo concreto de oraciones, a las que por su función específica dentro de las prácticas terapéuticas credenciales debemos denominar también «ensalmos», no son de hecho muy numerosas en la medicina popular europea. La siguiente oración algueresa (Cerdeña) empleada para sanar el «mal de l'os del cor» ${ }^{34}$ puede servirnos de ejemplo para ilustrar este tipo de ensalmos:

\author{
L'Esperit Sant és Déu, \\ lo Pare és Déu, \\ l'Esperit Sant és Déu, \\ la Fill és Déu. \\ En nom del Pare, del Fill, de l'Esperit Sant ${ }^{35}$.
}

del cielo, / estrella que canta, / estrella luminosa, / curad a esta dolorosa, / curad a este dolorido, / que de este mal sea liberado. / En nombre de Dios y de María, / más puede vuestra mano / que la mía.» Cfr. J. MARTf I PéreZ, op. cit. (1986), p. 313.

33 «Virgen Santa que me ve / curar a un angelillo del cielo, / por las llagas que sufrió / nuestro Señor en el Calvario, / dame fuerzas para matar / las lombrices que padece, / y que no vuelvan más / a este angelillo que es tuyo, / padeciendo (la dolencia de las) lombrices.» Cfr. V. LIS, op. cit., p. 220.

34 Se trata de una dolencia muy inconcreta cuyos malestares se manifiestan sobre todo en la región pectoral. A pesar de que se le atribuyen causas naturales el procedimiento terapéutico es siempre credencial. Cfr. J. MARTf I PÉREZ, op. cit. (1986), pp. 322-325.

35 «El Espíritu Santo es Dios, / el Padre es Dios, / el Espíritu Santo es Dios, / el Hijo es Dios. / En nombre del Padre, del Hijo, del Espíritu Santo." Cfr. J. MarTI I PÉREZ, op. cit. (1986), p. 324. 
Además de estas oraciones de naturaleza estrictamente laudativa que son de uso específico para el tratamiento de enfermedades determinadas, tenemos que mencionar también, dentro de este apartado, las oraciones de uso general de la Iglesia católica (padrenuestro, avemaría, gloria, salve regina, etc.), que asimismo pueden recitarse con una finalidad claramente complementaria y con frecuencia se añaden al ensalmo curativo específico, a fin de reforzar su eficacia. En aquellos casos, no obstante, en que estas oraciones de uso generalizado dentro del culto católico son el elemento principal e imprescindible de un proceso curativo particular, se potenciará generalmente el contenido ritual del rezo repitiéndolas un determinado número de veces, muy a menudo tres, siete o nueve, aunque en casos muy concretos este número puede ser mucho mayor. En el País Vasco, por ejemplo, para curar una picadura de serpiente deben rezarse veinte salves, numerándolas en voz alta de la última a la primera, inmediatamente después de haber ocurrido el percance; al accidentado se le aplica, además, un emplasto ${ }^{36}$. En algunas comarcas alemanas existe la creencia según la cual mediante el rezo de setenta y siete padrenuestros se puede curar cualquier enfermedad ${ }^{37}$. Aunque no he podido hallar datos al respecto, es muy posible también que en los tratamientos curativos de tipo credencial se reciten oraciones propias del culto católico de forma regresiva, empezando con la última palabra y terminando con la primera. Tal como ya es bien sabido, la lectura o el rezo regresivos son un recurso habitual dentro de las prácticas de tipo mágico. .

\section{Imperativos}

Este tipo de ensalmos que por su forma son evidentemente conjuros, a pesar de que a menudo se los denomine «oraciones», se caracterizan por el tono coactivo con que se dirigen a las fuerzas numénicas o mágicas -últimas responsables de la curación del enfermo- instando además en ocasiones a la enfermedad misma para que abandone el cuerpo. Muchos de estos ensalmos tienen un sabor claramente arcaico. El siguiente conjuro esloveno (Carintia) empleado para tratar las quemaduras, se recita después de haber soplado tres, cinco o siete veces sobre la herida:

36 Cfr. Ignacio M.* Barriola, La medicina popular en el País Vasco (San Sebastián, 1952), p. 125.

37 Cfr. C. SEYFAHRT, Aberglaube und Zauberei in der Volksmedizin Sachsens (Leipzig, 1913), p. 138. 
Danes je opeklina, jutri je bolečina, pojutrišnjem je zdravje 38 .

Ensalmo para curar los callos (País Vasco)

«Érekaitzen-ait, San Domingo'en izenian, zain handia chiardakiala» 39.

Tal como vimos en los ensalmos de tipo historiado, también en los de tipo imperativo se puede incluir un corto diálogo que, en este caso, se desarrolla con la misma enfermedad:

Ensalmo para tratar la roña (Cataluña)

-Ronya, ronyosa, bruta i fastigosa, què hi fas aquí? -Aquí m'estic per fer martiri a en...

-Mala ronya, fuig d'aquí, fes-ne via pel cami; trobaràs a Sant Martí, sos passos vulgues seguir, que en bon lloc et portarà, on no faràs patir ni penar.

Si Sant Martí no vols seguir, trobaràs Nostre Senyor, que et donarà molt de bo; si no vols anar amb Nostre Senyor, trobaràs la Verge Maria, que et darà molt bona guia, tant si fuges de nit com si fuges de dia; $i$ tot això es veritat, com Jesús és nat, Jesús és crucificat, i Jesús és ressuscitat. A honra i glòria de la Santíssima Trinitat, que el mal d'en...

sigui ben aviat curat 40 .

38 «Hoy la quemadura, / mañana el dolor / pasado mañana la salud.» Cfr. P. KošlR, op. cit., p. 65.

39 «Te ordeno, en nombre de Santo Domingo que el gran nervio se re seque.» Cfr. I. M.' BARRIOLA, op. cit., p. 113.

40 «-Roña, roñosa, / sucia y asquerosa, / ¿qué haces aquí? / -Aquí estoy para 
En ocasiones, no basta con dirigirse a la enfermedad con un tono imperativo, sino que se hace uso de la imprecación, recibiendo entonces el ensalmo un carácter realmente agresivo:

Ensalmo para el herpes (Galicia)

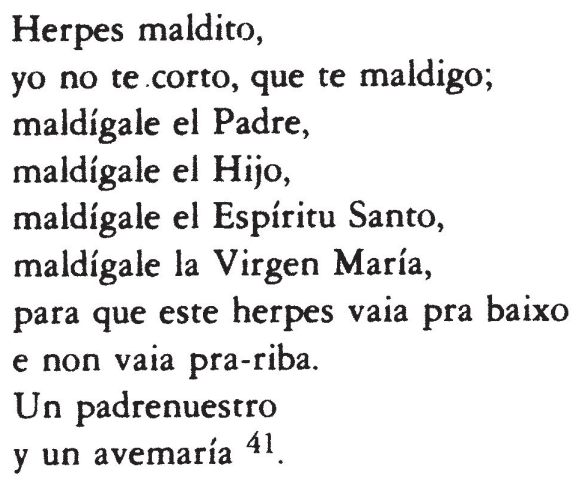

\section{Enumerativos}

Estas oraciones o conjuros tienen como característica principal el hacer uso de una enumeración invirtiendo, no obstante, su orden natural, como si a medida que se vaya efectuando la progresión regresiva fuese desapareciendo el elemento morboso del cuerpo enfermo. Entre los ensalmos destinados a curar a los niños de las lombrices intestinales encontramos un buen número de ellos que pertenecen a este grupo:

Asturias

As llombrigas eran nueve;

de nueve volvéronse ocho; de ocho volvéronse siete; de siete volvéronse seis; de seis volvéronse cinco; de cinco volvéronse cuatro; de cuatro volvéronse tres;

hacer martirio a... / - Mala roña, fuera de aquí, / vete por el camino; / encontrarás a San Martín, / quieras seguir sus pasos, / que a buen sitio te llevará, / donde no harás sufrir ni penar. / Si a San Martín no quieres seguir, / encontrarás a Nuestro Señor, / encontrarás a la Virgen María, / que te dará muy buena guía, / tanto si huyes de noche / como si huyes de día; / y todo esto es verdad, / como Jesús ha nacido, / Jesús ha sido crucificado, / y Jesús ha resucitado. / $\mathbf{A}$ honra y gloria / de la Santísima Trinidad, / que el mal de... / sea pronto curado.» Cfr. J. AMADES, op. cit., p. 986.

41 Cfr. V. Lis, op. cit., p. 199. 
de tres volvéronse dos;

de dos volvéronse una...

Todas las corto,

nin ye fago mal.

Ofrezco a Dios y a la Virgen María

un padrenuestro y una avemaría 42 .

\title{
Cerdeña
}

\author{
Lunedi santo, \\ martedi santo, \\ mercoledi santo, \\ giovedi santo, \\ sabato santo, \\ e domenica di Pasqua. \\ Tutti vermi di... \\ che se ne vadano 43
}

Pero el ensalmo de tipo enumerativo-regresivo se emplea también para otros muchos tipos de enfermedades:

\author{
Ensalmo para la caída de matriz (Cataluña) \\ Mare moguda té nou branques, \\ qui de nou en treu una, en resten vuit. \\ Mare moguda té vuit branques, \\ qui de vuit en treu una, en resten set. \\ [...sis...cinc...quatre...tres...] \\ Mare moguda té dues branques, \\ qui de dues en treu una, en resta una. \\ Ni per juntes, ni per puntes, \\ ni per amunt, ni per avall, \\ restareu allà on la Verge us ha posada 44
}

Ensalmo contra las escrófulas (País Vasco)

\footnotetext{
42 Cfr. C. Cabal, op. cit., p. 576.

43 Tal como podemos apreciar, este ensalmo no se recita en lengua sarda sino italiana. «Lunes Santo, / Martes Santo, etc. / y Domingo de Pascua. / Todas las lombrices de... / que se vayan.» Cfr. J. MARTf I Pérez, op. cit. (1986), p. 326.

44 «Matriz desplazada tiene nueve ramas, / quien de nueve saca una quedan ocho. / Matriz desplazada tiene ocho ramas, / quien de ocho saca una, quedan siete / etc. / Matriz desplazada tiene dos ramas, / quien de dos saca una, queda una. / Ni por juntas, ni por punta, ni por arriba, ni por abajo, / os quedaréis alli donde la Virgen os ha puesto.» Cfr. H. GuITER, op. cit., p. 306. Véase también la variante reportada por J. AMADES en op. cit., p. 977.
} 
Angabillak dire bederatzi, bederatzitik zortzi, zortzitik zazpi, zazpitik sei, seitik bortz, bortzik lau, lautik iru, irutik bi, bitik bat.

Angabillak egin dezatela zapart ${ }^{45}$.

\section{Ensalmo contra el mal de ojo (Bosnia)}

«Urok sjedi na pragu uroćica pod pragom, urok skoći te uroćicu uguśi,

Uroka od 9 oka

uroka od 9 oka 8

uroka od 7 oka 6

[etc. ...]

uroka od 2 oka 1

uroka od 1 oka - 46 .

Excepcionalmente encontramos también algunos ensalmos en los que, antes de efectuar la enumeración de forma regresiva, se recitan progresivamente. Th. Trade nos da un ejemplo de estos ensalmos recogido en Italia meridional, muy similar al conjuro que hemos podido ver líneas más arriba, en el que se enumeran los días de la Semana Santa ${ }^{47}$.

\section{Analógicos}

Existe un interesante grupo de ensalmos muy difundidos en Europa los cuales están constituidos por una fórmula de analogía según el esquema básico siguiente:

45 "Nueve son las "angabillas": / de nueve, ocho; / de ocho, siete; / etc. / de dos, una. / Que revienten las "angabillas".» Cfr. José Antonio de DONOsTIA, «Oraciones, prácticas religiosas y medicinales populares", Cuadernos de Etnología y Etnografía de Navarra, 10 (1972), p. 30.

46 «El que embruja está sentado en el umbral de la puerta, la que embruja está sentada bajo el dintel. El que embruja salta y estrangula a la que embruja, / de nueve uno que embruja, / uno que embruja de nueve, ocho / uno que embruja de ocho, siete / etc. / uno que embruja de dos, uno, / uno que embruja de uno, nada.» Cfr. S. SEl.KimanN, op. cit.. I, pp. 373-374.

47 Cfr. Th. TRADE, Das Heidentum in der römischen Kirche. Bilder aus dem religiösen und rittlichen Leben Süditaliens (Gotha, 1889-1891), II, p. 85. 
Si « $x »$ es cierto,

«y» también lo será.

Tratándose «x» de algo considerado como existente y real mientras que «y» representa el efecto deseado; en el caso de los ensalmos terapéuticos, este efecto será lógicamente la curación del enfermo. Así, por ejemplo, para prevenir los «malos aires» se dice en Galicia:

\author{
Vaite mal \\ vente ben \\ como Jesús \\ nacéu en Belén 48 .
}

es decir, «tan cierto es que Jesús nació en Belén, como que el mal se irá». El origen de este tipo de ensalmos hay que buscarlo naturalmente en el principio similia similibus de la magia homeopática. Luis Gil, en su conocido trabajo sobre la medicina popular en el mundo clásico ${ }^{49}$, nos relata una complicada práctica terapéutica de tipo credencial procedente de Grecia, práctica que finaliza depositando un puñado de sal sobre la raíz de una determinada planta mientras se dice:

Lo mismo que estos granos de sal no crecerán, tampoco crezca la dolencia de fulano o fulana 50.

El sentido del ritual es, pues, declarar una relación de analogía entre los granos de sal y la dolencia, resultando consecuentemente de ello el razonamiento:

Los granos de sal no crecen,

los granos de sal son lo mismo que la dolencia,

por consecuencia la dolencia no crecerá.

El «hecho mágico» consiste evidentemente en relacionar la primera premisa con la conclusión del silogismo mediante la segunda premisa. Lo mismo sucede con el siguiente ritual que, todavía hoy, se practica en Cerdeña (l'Alguer) para eliminar las verrugas: Se toma un tomate al que se le hacen tantos agujeros como verrugas se tengan mientras se dice:

48 Cfr. Carmelo Lisón Tolosana, «La 'sabia' gallegan, M. Kenny y A. de Miguel, op. cit., p. 201.

49 L. GIL, op. cit.

50 L. GIL, op. cit., p. 243. 
Així com pudi la pomata, que pudi la berruga de... 51

El tomate se entierra y las verrugas desaparecerán a medida de que el tomate se vaya pudriendo. En este caso, el «hecho mágico» consiste en crear una relación de analogía entre el tomate agujereado y estos antipáticos aunque inofensivos tumores cutáneos.

No obstante, existe una pequeña diferencia entre estos dos ensalmos últimos y el ensalmo gallego que hemos visto en primer lugar. Aquéllos no hacen sino acompañar un ritual propio de la magia homeopática en el que la relación de analogía se establece no sólo con la recitación del ensalmo sino también por el poder mágico del ritual en sí; la analogía se establece a nivel material (dolencia $=$ granos de sal, verruga $=$ tomate). En el ensalmo gallego, en cambio, se realiza la analogía en un registro abstracto. El «hecho mágico» (la segunda premisa del silogismo) viene dado por la fuerza misma del ensalmo que relaciona ambas cláusulas entre sí por el hecho de "tener» las dos la cualidad de ser verdaderas: ambas cláusulas son análogas porque ambas cláusulas «son» verdaderas, y negar una de ellas equivaldría lógicamente a negar también la otra.

Sin duda alguna, este tipo de ensalmos tienen un cierto carácter coactivo pero a diferencia de los que anteriormente hemos denominado «imperativos», en ellos la curación deseada no será el resultado directo de un mandato (del curandero, personaje celestial, espíritu, etc.), sino el resultado del cumplimiento de una ley «natural» dentro del registro mágico. Veamos a continuación otros ejemplos de este tipo de ensalmos:

Ensalmo para curar las quemaduras (Bélgica)

Feu du ciel perds ta chaleur comme Judas a perdu sa coleur quand il trahit notre Seigneur 52.

Ensalmo para curar las quemaduras (Francia, Tarn)

51 «Así como se pudre el tomate, / que se pudra la verruga de...» Cfr. J. Martf I PÉREZ, op. cit. (1986), p. 328.

52 «Fuego del cielo / pierde tu calor / como Judas perdió su color / cuando traicionó a nuestro Señor.» Cfr. Paul Hermant, y Denis Boomans, la médecine populaire (Bruxelles), p. 156. 
Feu contre feu, arrête le feu comme Judas a trahi le bon Dieu 53 .

\title{
Ensalmo contra el dolor (Alemania)
}

$\mathrm{Zu}$ Bethlem ist Christus geboren, in Nazareth erzogen, in Jerusalem gekreuzigt, so gewiss als diese Worte sein [sic], so gewiss wirst du von allen Schmerzen und Plagen befreit sein ${ }^{54}$.

\section{Transferenciales}

Por último, de la misma manera que hemos visto reflejado el principio de la magia analógica en el anterior grupo de ensalmos, también encontramos una serie de conjuros con finalidades terapéuticas que están en directa correspondencia con la magia denominada de contacto o transferencial. En este caso, se perseguirá pasar mediante el ensalmo la enfermedad del aquejado a otro ser vivo u objeto, consiguiendo de esta manera la recuperación de la salud. Estos ensalmos acompañan siempre un ritual terapéutico-credencial propio de la magia transferencial a diferencia de los que hemos visto anteriormente que, en ocasiones, pueden por ellos mismos y sin ritual adicional pretender la curación del enfermo. Así, por ejemplo, en las Islas Canarias para librarse de las verrugas se deberá llamar a la puerta de un desconocido al cual se le dirá:

\author{
Verrugas traigo \\ verrugas vendo \\ aquí las dejo \\ y me voy corriendo 55 .
}

abandonando prestamente el lugar una vez se hayan recitado estos versos. Un ensalmo parecido se conoce también en Extremadura para curar las

53 «Fuego contra fuego, / detiene el fuego / como Judas traicionó al Buen Dios.» Cfr. Robert JALBY, Sorcellerie et médecine populaire en Languedoc (Nyons, 1974), p. 163.

54 «Cristo nació en Belén, / fue criado en Nazaret, / crucificado en Jerusalén, / tan cierto como estas palabras son, / tan cierto es que te librarás de tanto dolor y pena.» Cfr. C. SEYFAHRT, op. cit., p. 128.

55 Cfr. J. A. SÁnChez Pérez, op. cit., p. 297. 
fiebres palúdicas. El enfermo tiene que salir de su casa en ayunas a primeras horas del día provisto de una varita - si es posible de avellano-, y sin hablar con nadie ni volver la cabeza tiene que dirigirse a un cruce de caminos o a una fuente. Allí, debe trazar una cruz en el suelo con ayuda de la varita mientras dice:

\section{Calenturas traigo \\ calenturas tengo \\ ¿quién me las compra? \\ ¡Yo no las quiero! 56}

Seguidamente tiene que arrojar la varita al suelo y volver a casa también esta vez sin hablar con nadie ni girarse. La primera persona que recoja la varita del suelo contraerá las fiebres, librando de esta manera a la persona que haya realizado el ritual. En Galicia, para curar la ictericia se orina durante nueve mañanas seguidas sobre una planta denominada «marrubio» (Marrubium vulgaris) diciendo tres veces sin tomar aliento:
A visitarte vengo marrubio
entre la luna y el sol
que me quites la tercina
y me vuelvas el color 57 .

Según una creencia belga, se puede pasar el hipo a los conejos; para ello hay que decir tres veces sin respirar el siguiente conjuro valón:

$$
\begin{aligned}
& \text { D'jà l'hiquette, } \\
& \text { Jel donne à m'robette, } \\
& \text { si m'robette nel vau nin } \\
& \text { quel mal rejette } 58 \text {. }
\end{aligned}
$$

Una gran parte de los ensalmos terapéuticos que conocemos se adscriben de manera clara a una de las diferentes categorías de la tipología que hemos esbozado. No obstante, encontraremos también ensalmos que a primera vista pueden pertenecer a dos categorías distintas. Pero analizando detenidamente estas oraciones o conjuros, veremos que muy a

\footnotetext{
56 Cfr. A. Castillo de LuCas, Folkmedicina (Madrid, 1958), p. 29.

57 Cfr. J. RodrfGuez LÓPEZ, Supersticiones de Galicia y preocupaciones vulgares (Lugo, 1974), p. 126

58 «Tengo el hipo, / lo doy a mi conejito, / si mi conejito no lo quiere / que me lo quite.» Cfr. P. HeRmant, op. cit., p. 89.
} 
menudo se componen de dos o más partes que, aunque recitadas conjuntamente como si de un solo ensalmo se tratara, poseen una cierta autonomía, hecho que apunta hacia una diferente procedencia de cada una de ellas. En realidad, por lo que concierne a la formación de variantes dentro de la literatura oral popular, la adición de dos textos de diverso origen es precisamente uno de los factores determinantes. Un ensalmo concreto, tal como la canción, el cuento o la leyenda, puede haberse formado a resultas de la fusión de dos ensalmos diferentes. Un ejemplo ilustrativo de este fenómeno lo tenemos en el conjuro provenzal que ofrecemos a continuación, el cual se compone de dos estrofas de diferente carácter y que muestran entre sí una innegable autonomía; el ensalmo no pierde sentido si eliminamos una cualquiera de ellas. En este caso se trata de un ensalmo de carácter mixto en el que se conjugan los elementos imperativo y analógico:

Ensalmo contra la queratitis (Languedoc)

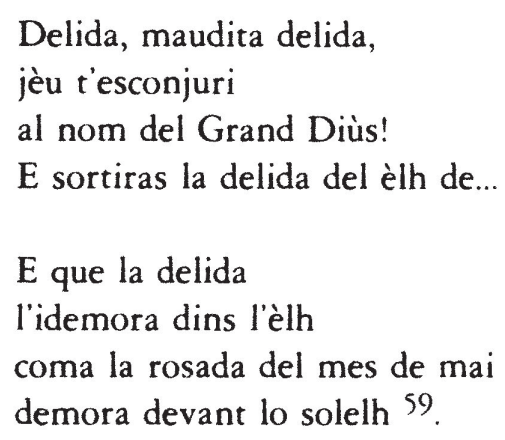

En el siguiente ejemplo, el fenómeno de la adición en las circunstancias genéticas del ensalmo son mucho más claras:

Ensalmo contra el mal de ojo (Cerdeña, l'Alguer)

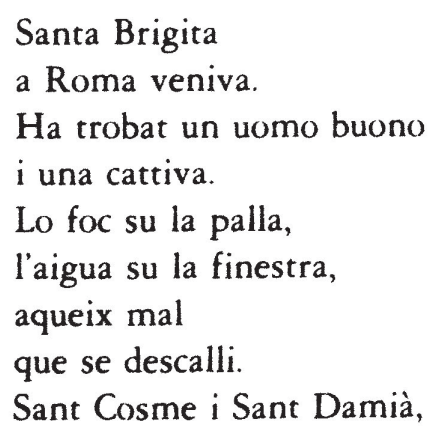

59 «'Delida' [queratitis], maldita 'delida', / yo te conjuro / en nombre del Gran Dios! / Y tú sacarás la 'delida' del ojo de..." "Y que la 'delida' / permanezca en su ojo / como el rocío del mes de mayo / permanece ante el sol.» Cfr. R. JALBY, op. cit.. p. 171. 
aqueix mal

que se pugui descallar 60

En la primera mitad de este ensalmo alguerés entrevemos una alusión a la leyenda hagiográfica - mencionada en páginas anteriores ${ }^{61}$ del santo que solicita albergue en casa de un matrimonio. La procedencia italiana de estos versos es inequívoca, puesto que aparte del hecho de ser una leyenda muy difundida en el mezzogiorno italiano, se aprecia en ellos la mezcla de dos registros lingüísticos diferentes: el alguerés - dialecto catalán- y el italiano. La segunda mitad, en cambio, es recitada íntegramente en alguerés, y por su morfología pertenece al tipo de oraciones de procedencia algueresa que se recitan contra el mal de ojo. Añadamos además que las oraciones terapéuticas que hacen alusión a esta leyenda hagiográfica italiana acostumbran a ser recitadas para sanar el dolor de vientre, circunstancia lógica puesto que esta dolencia fue precisamente el castigo que en la leyenda recibió la mujer por su mal comportamiento hacia el santo. No obstante, a resultas de la fusión de la oración italiana con la algueresa aquella ha perdido su función primitiva.

El fenómeno de la adición es muy corriente en la literatura oral popular, pero en el caso de los ensalmos hay que tener en cuenta además que la adición es un recurso idóneo y muy frecuente para la cristianización de conjuros de procedencia pagana.

Quedan todavía sin clasificar una serie de ensalmos de los que actualmente no podemos establecer, de manera precisa, la significación de sus versos, ya sea debido a la paulatina deformación que han ido experimentando a través de la difusión oral, ya sea por su primitivo contenido esotérico que, si bien puede haberse perdido para los mismos ensalmadores, no es óbice para que se sigan recitando de manera más o menos fiel a través del tiempo. He aquí dos ejemplos:

Ensalmo para el dolor de vientre (Cataluña)

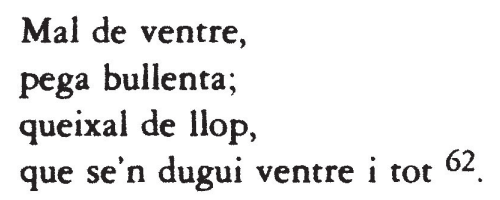

61 «Santa Brígida / a Roma iba. / Encontró un hombre bueno / y una [mujer] mala. / El fuego sobre la paja, / el agua en la ventana, / este mal / que se deshaga. / San Cosme y San Damián, / este mal / que se pueda deshacer.» Cfr. J. Martf I PÉREZ, op. cit. (1986), p. 314.

61 Véase p. 23 de este artículo.

62 «Dolor de vientre, / pez hirviente; / muela de lobo, / que se lleve vientre y todo.» Cfr. J. AMADES, op. cit., p. 980. 
Ensalmo para la palpitación cardíaca (Alemania, Turingia)

Wolf ohne Lunge,

Storch ohne Zunge,

Taube ohne Galle,

Herzgespann du must fallen! 63 .

Esta tipología de los ensalmos que hemos visto en páginas anteriores nos puede ser de utilidad a la hora de intentar poner un poco de orden en el cuantioso material etnográfico de que disponemos. No obstante, hemos de tener bien presente que toda tipología es una mera abstracción que si no se entiende como es debido y se ignoran sus limitaciones puede ser también una manera de falsear la realidad. Obedeciendo esta tipología a un análisis de tipo inmanente, no basta lógicamente para llegar a comprender de manera sastisfactoria el sentido ritual terapéutico en su totalidad. No tan sólo por el hecho de que el ensalmo es por lo general únicamente una parte del acto curativo de signo credencial, sino porque, muy a menudo, su función dentro de él es tan sólo estructural. Desde el punto de vista emic, el contenido estricto del ensalmo no es siempre lo más importante. Tengan el carácter que tengan, sean de tipo impetrativo o imperativo, de procedencia exclusivamente religiosa o de claro origen precristiano, muy a menudo se les denominará sencillamente «oraciones». Lo que realmente cuenta en el momento de ejecutar un ritual concreto es poder disponer de «el ensalmo» con el inherente poder sobrenatural que le asigna la tradición. El carácter que pueda tener no importará demasiado al ensalmador, siempre naturalmente que su contenido no se halle en franca disonancia con los principios fundamentales religiosos propios del sistema cultural.

JOSEP MARTI I PEREZ

CSIC. Barcelona

63 «Lobo sin pulmón, / cigüeña sin lengua, / paloma sin hiel, / excitación Ipalpitaciones] del corazón debes caer [cesar]!». Cfr. C. SeYfahrT, op. cit., p. 126. 
En la medicina popular europea, el ensalmo terapéutico tiene una importancia de primer orden. Aunque ligado siempre a un procedimiento de tipo credencial o empírico, el ensalmo - por lo que a su formación y difusión se refiere- está sujeto a las mismas leyes que podemos observar en otros géneros de la literatura oral tradicional. La finalidad del presente trabajo ha consistido en elaborar una tipología del ensalmo terapéutico basada en criterios formales y de contenido. Para ello se han tomado en consideración ejemplos procedentes de las más diferentes regiones del Viejo Continente.

In the Eyropean folk medicine, the healing prayers have a great deal of importance. These prayers, which are always bound to credencial or empirical procedures, are - regarding to its formation and diffusion- under the same laws than the other genres of the traditional oral literature. The aim of this work is to elaborate a typology of the healing prayers according to formal and semantic criteria. For this purpose, examples from very different European regions have been taken into account. 